\title{
THE MOTOR SKILLS FOR PERFORMING MANIPURI PUNG CHOLOM
}

\author{
Leitanthem Santosh Singh $1 \square$ (iD) \\ Research Scholar, Department of Dance and Music, Manipur University, India
}

Received 04 September 2021

Accepted 08 October 2021

Published 26 November 2021

\section{CorrespondingAuthor}

Leitanthem Santosh Singh, leitanthem.santosh859@gmail.com

\section{DOI}

10.29121/shodhkosh.v2.i2.2021.49

Funding: This research received no specific grant from any funding agency in the public, commercial, or not-for-profit sectors.

Copyright: (C) 2021 The Author(s). This is an open access article distributed under the terms of the Creative Commons Attribution License, which permits unrestricted use, distribution, and reproduction in any medium, provided the original author and source are credited.

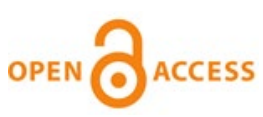

\section{ABSTRACT}

Manipuri Nata-Sankirtana is a unique type of performing art form where Manipuri male musicians sing Sankirtana using musical instruments such as Pung (Manipuri percussion musical instrument) by Pungyeiba (Pung player), Kartal (Manipuri cymbal) by Eshei-sakpa (singers), and Moibung (Conch Shell) by Moibungkhongba (conch blower) by following its prescribed sequence. The percussion musical instrument, Pung is the soul of such performance. It is necessary to know how Pung Cholom (the dexterous and vigorous movements of the body from head to toe in tune with the beats of playing Pung simultaneously in a creative manner by the Pungyeiba) is done and what are the motor skills involved in performing it. The discussion has the following objectives: Identifying the different parts of the body involved in doing Pung Cholom, knowing the basic foundations for playing Pung, and understanding the basic motor skills for performing Pung Cholom. It uses descriptive qualitative method. This utilizes the tools and techniques of interview and observation. This will bring out the different aspects of Manipuri Pung Cholom helping in the learning area of psychomotor skill, giving global benefits in performing arts.

Keywords: Cholom, Guru-Shishya Parampara, Manipuri Nata-Sankirtana, Motor Skills, Pung Cholom

\section{INTRODUTION}

Manipur, a land situated in the north-eastern part of India, is well known for its diverse art and culture worldwide. A particular mention can be made of the famous performing art form, Manipuri Nata-Sankirtana. Manipuri NataSankirtana is a unique type of performing art form where Manipuri male musicians or artistes sing Sankirtana using musical instruments such as Pung (a Manipuri percussion musical instrument) by Pungyeiba (Pung player), Kartal (a Manipuri cymbal) by Eshei-sakpa (singers or vocalist) and Moibung (Conch Shell) by Moibungkhongba (conch blower or conch sound producer) by following its prescribed sequence. It is also included in UNESCO's Intangible Cultural Heritage List of Humanity as Sankirtana: ritual singing, drumming, and dancing of Manipur, on 4th December 2013.

The Manipuri Nata-Sankirtana education was developed under the disciplined and bhakti manner of Guru-Shishya parampara, where pupils stay at the house of Guru or come from their respective places every day. The Guru is considered as the second parent. Here, students do most of the domestic works of Guru, thereby learning the socialization process in many ways. The teacher-taught relationship is very cordial and intimate. The Guru is regarded 
full attention to teaching. The first-ever Nata-Sankirtana performance was done in the year 1779 A.D., during the reign of King Bhagyachandra. He ruled from 17591798, which preceded the first Ras Lila (Manipuri Classical Dance) performance at Langthabal Palace. The King himself was the head Pung performer (Pungkok-yeiba) on that ritualistic Nata-Sankirtana performance.

Manipuri Nata-Sankirtana uses three musical instruments. They are: -

1) Pung (a Manipuri percussion musical instrument) by Pungyeiba (Pung player)

2) Kartal (a Manipuri cymbal) by Eshei-sakpa (singers or vocalist)

3) Moibung (Conch Shell) by Moibungkhongba (conch blower or conch sound producer)

The performance done by using a Pung percussion instrument is called Pung Cholom. It requires many motor skills to do it, which is not simple and easy to acquire. Kerr (1982) stated that motor skill is any muscular activity directed to a specific objective. So, motor learning is the first requirement for performing Pung Cholom, acquired through practice and experience. The motor skills for doing such performance range from simple skills to highly complex skills. It needs to study the cognitive aspects of motor skills acquisition.

\section{MANIPURI PUNG}

Manipuri Pung (Figure 1) is a spindle-shaped percussion musical instrument made up of a hollow wooden body with a rough or somewhat smooth surface inside, the two ends of which are covered with leather caps (Pung Maru and Pung Manao) (Figure 2). The two ends are tied together by leather straps called Sawun Maree. This percussion instrument falls under the Alingya anaddha or avanaddha vadya/drum, played by hands suspended from the neck-shoulder position. The membranes of animal hide used in making this instrument are from cow, calf, buffalo, bull/ox, etc.

Babu (1968) opined that in Manipur, Pung was understood for knowing time like hours. So, the term Pung percussion musical instrument was used to denote the rhythmic measurement of taala in singing and dancing.

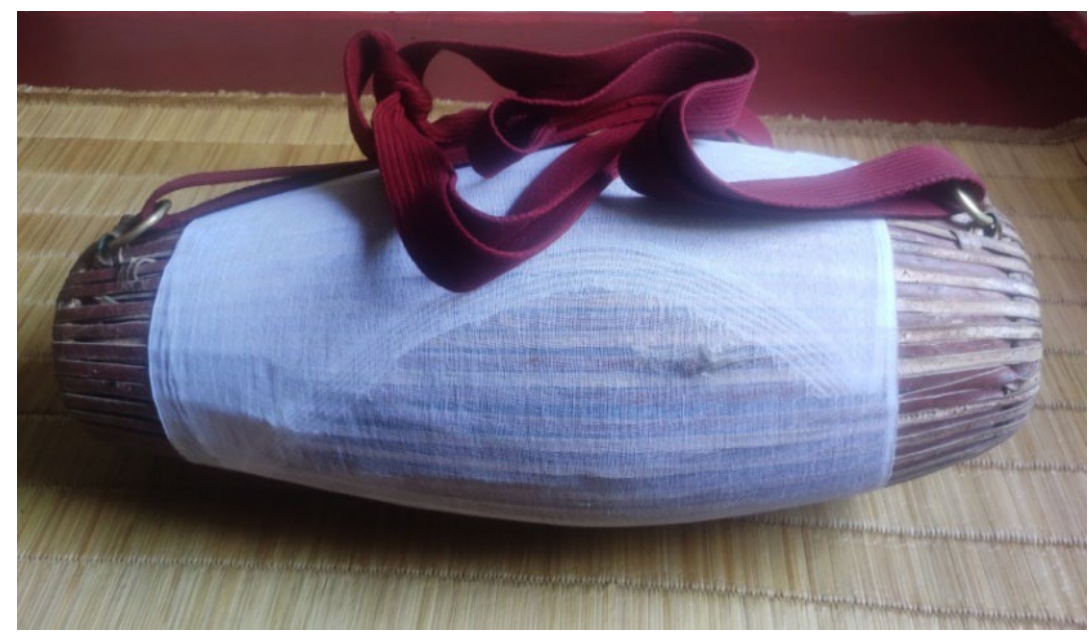

Figure 1 Manipuri Pung in Horizontal Position 


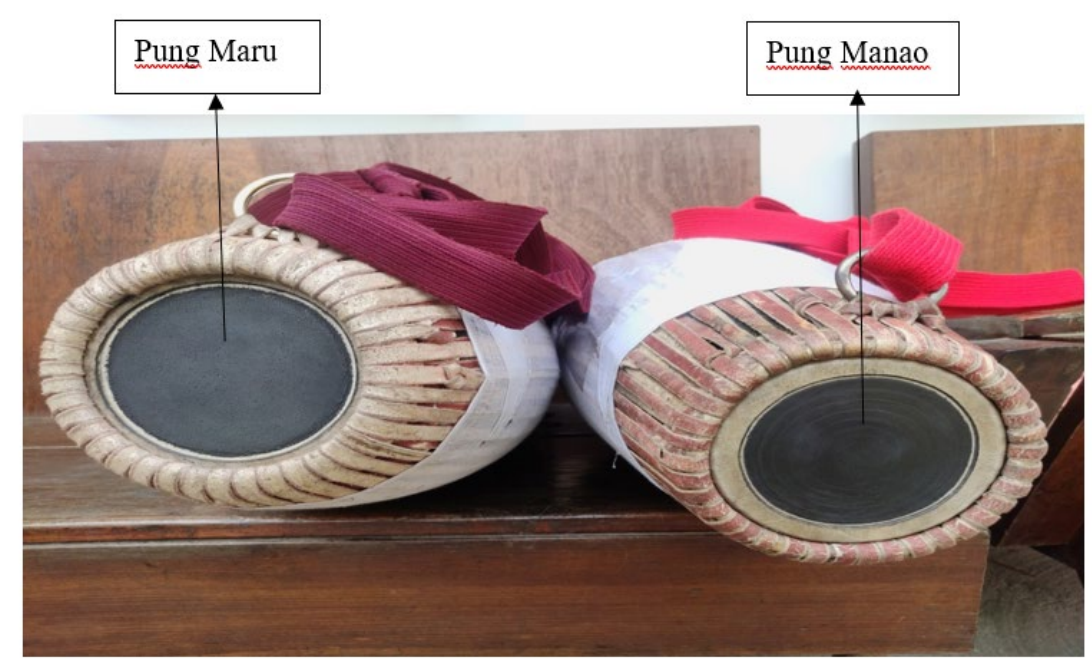

Figure 2 Pung Maru and Pung Manao

\section{CHOLOM}

Cholom is the body movements and gestures performed by the Nata-Sankirtana artistes by using the music of Pung and Kartal with or without the accompaniment of songs in specific time measures and rhythm.

Danisana (2012) writes that the literal meaning of the word- Cholom in Manipuri language can be broken into two parts Cho, a derivative of the root word Chat meaning to go or to move, and Lom indicating the limit or zenith of a thing. So, Cholom is the most dexterous and refined part of all the body movements from head to toe of the Nata-Sankirtana performing artistes. Naturally, Nature is the source of all the existing storehouses of art and culture, which designates the human society from the living entities. Likewise, most of the movements of cholom are imbibed and refined from natural phenomena.

Rangitabali (2004) discussed that the Manipuri word- Cholom is derived from the Sanskrit word-Chalan, a composed movement in sequence. Generally, it is taken as a distinct structuralized rhythmic body movement and expression from head to toe for men accompanied by the songs and music of Pung and Kartal. It connotes more of tandav bhava, and from the word chalan, it is developed into cholom.

Though Cholom is derived from Chalan, all body movements and expressions used are the original creative products of Manipur, which is unique in itself. Cholom has more of Tandav body movements with some Lasya elements while making bhakti and devotion. It is part and parcel of Manipuri Nata-Sankirtana ritualistic or entertainment performance. In ritualistic performance, Cholom is always bound within the core of bhakti and devotion. However, it crosses the bhakti boundary to entertain the audience in stage performance adding many acrobatic and entertaining movements.

\section{MANIPURI PUNG CHOLOM}

Manipuri Pung Cholom is the dexterous and vigorous movement of the body from head to toe in tune with the beats of playing Pung simultaneously in a creative 
manner by the Pungyeiba. The playing of Pung is done simultaneously along with body movements in performing Pung Cholom.

Having a keen sense of balance, rhythm and creativity is the utmost requirement for doing Pung Cholom. Many acrobatic movements are also part of it. Pung Cholom can be done in the following manner: -

1) Pung Cholom in the ritualistic Nata-Sankirtana performance

2) Pung Cholom for stage performance in solo or group (Figure 3)

3) Pung-Kartal Cholom in group for stage performance (Figure 4)

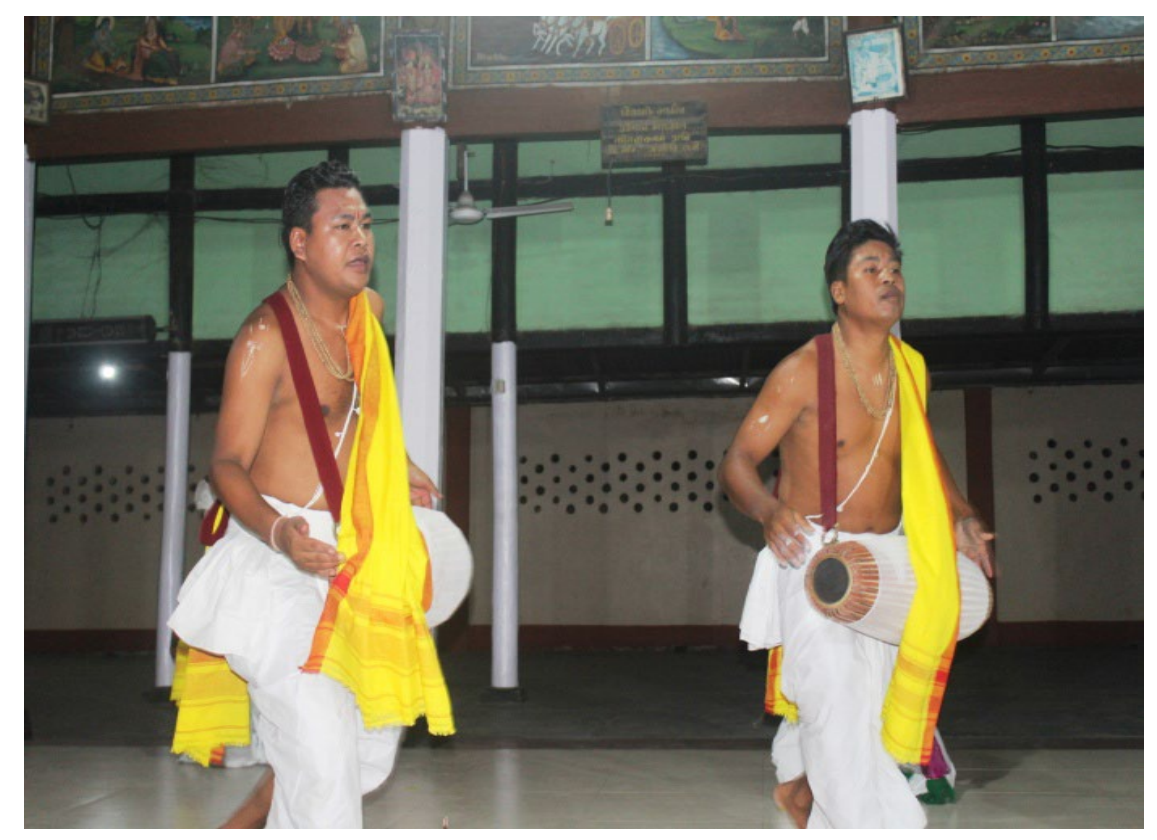

Figure 3 Pung Cholom in group

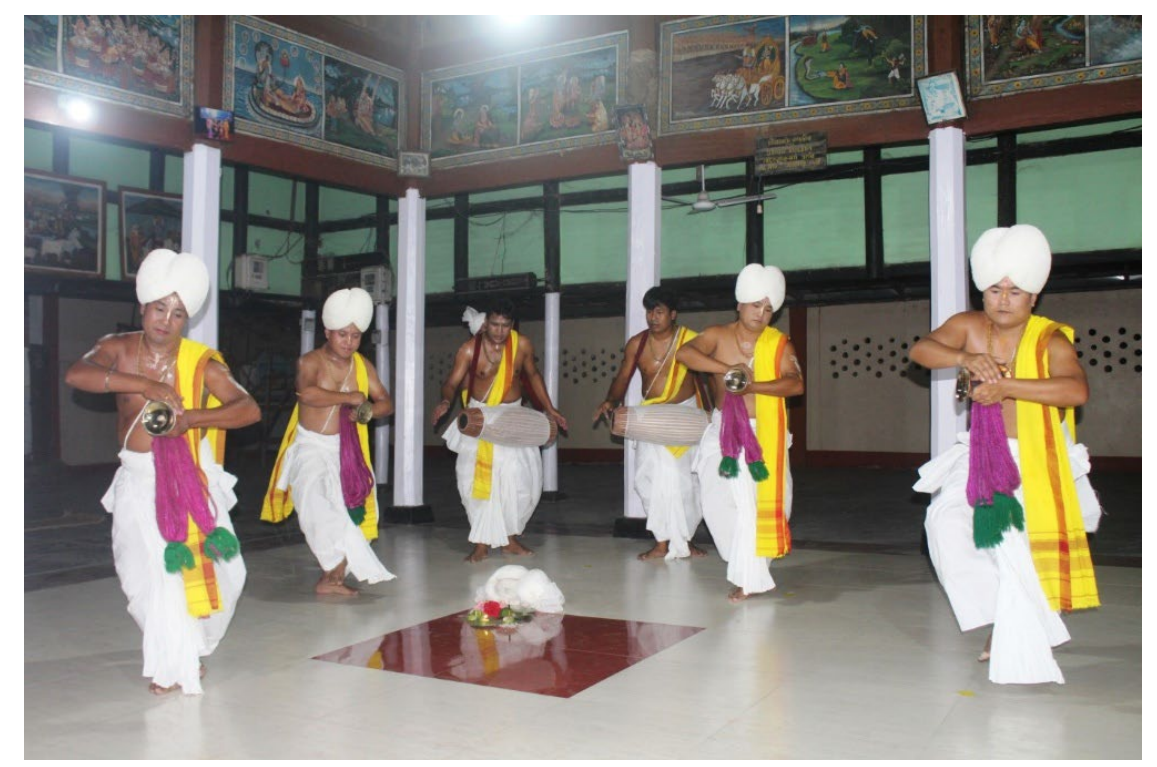

Figure 4 Pung-Kartal Cholom for stage presentation 


\section{OBJECTIVES OF THE STUDY}

The following are the objectives of the present study: -

1) To identify the different parts of the body involved in doing Pung Cholom

2) To know the basic foundations for playing Pung

3) To understand the basic motor skills for performing Pung Cholom.

\section{METHODOLOGY OF THE STUDY}

1) Method- Descriptive Qualitative method is used in the present study

2) Tools and Techniques- The tools and techniques of interview and observation (both participant and non-participant of the researcher) is being used in the present study

\section{FINDINGS AND ANALYSIS}

Using interviews and observation, the researcher identifies the different parts of the body (Figure 5) involved in performing Pung Cholom.

While performing Pung Cholom, most parts of the body from head to toe are used. Systematically, the body parts are divided into three parts. They are: -

1) Head along with neck

2) Body from shoulder to waist along with hands

3) The body below waist- Legs along with buttock

The sub-divisions of those mentioned above, three main divisions of different body parts, are again identified. They are listed below: -

1) Head and neck- In this portion, four different sub-divisions are made, used differently in Nata-Sankirtana performance.

- Head - The movement of the head in nata-sankirtana performance is generally known as koklei or kokhai. The head is used in four different names viz. nikpa (shaking of the head is done while playing Pung in high and fast tempo), haiba (the head is moved left and right dased on the rhythm and taal of the song), leiba (movement of the head in all direction while doing Pung cholom) and khatpa (the head is moved instantly while changing the tempo of playing Pung in the higher note along with cholom)

- Neck - The neck always goes with the head. But it has got its ten different names based on how it is used viz. akhakpa (one side of the head is moved a whole circle along with neck), ahunba ( the head is put upward along with neck), chatpa (movement of the head with the neck on left and right side, to and fro with grace), apheiba (going the whole body on one side showing the movement of the head with neck), taminnaba ( head and neck fall simultaneously where the body falls), hanba (going back of the head with neck), thaba (putting the head and neck forward), cheptha (finishing the playing of Pung on the side), athekpa (when Pung cholom is about to finish, the chin is put upward 
and then in the normal position finishing it) and sepchatnaba (going the head and neck along with the body while doing cholom)

- Eyes - In Manipuri, it is known as Mityeng. The eyes play a significant role as everything is performed by looking. It has got three different types which are named based on the distance of looking and placing our eyes viz. anakpa (the eyes are placed about $2.6 \mathrm{~m}$ away), mayai (the eyes are placed about $4.3 \mathrm{~m}$ away), and arappa (the eyes are placed about $6 \mathrm{~m}$ away)

- Mouth/Lips - The different modes of putting the lips indicates different modes of expression while performing. It is classified into four different gestures viz. chumna leiba (lips in the normal position), chikpa (the gesture when someone is angry), tumthokpa (lips are put somewhat forward), and chingthokpa (the jaws are put wide)

2) Body from shoulder to waist and hands- This second division of body parts is again divided into eight different portions according to the different uses and placement while performing nata-sankirtana.

- Shoulder - The shoulder can be used only left or right side or both sides depending on the cholom done. It has got three different sub-types on how and where the shoulder is placed, viz. hikthaba (the shoulder is placed somewhat low from normal position), inkhatpa (the shoulder is placed somewhat high from the normal position), and khappa (the moving of the shoulder up and down while doing Cholom)

- Chest - It is the chest of the nata-sankirtana artiste, which shows the correct posture and bhakti while doing cholom. So, six different names are identified based on where the chest is placed during cholom performance, viz. aroongba (the chest is placed somewhat forward from the normal condition), awuppa (the chest is placed somewhat inward from the normal position), taba (putting the chest after finishing playing the Pung), cheppa (moving of the chest left and right while placing the legs left and right respective in doing Cholom), hunba (placing the chest along with the whole body in doing Cholom) and leiba (moving the chest left and right and a complete circle in doing Cholom)

- The upper back surface of the body - The upper back surface of the body is changed into different postures based on the tempo- slow, medium, and fast pace of playing the instrument (Pung or Kartal). Two different types are understood, viz. yang tingba (making the body straight) and yang konba (making the body somewhat curve)

- Abdomen/Stomach/Belly - The abdomen part of the body is always kept in the exhalation condition of normal breathing, which is the combination of puuk kangthokpa (stomach is spread), swar hanthaba (normal breathing after exhalation), and chaning tana inthaba (pelvis is kept regular)

- Waist - Again, the waist occupies a significant part in attaining the correct posture of doing cholom. It has three different types, which are named according to where the waist is placed along with the wholebody parts viz. thekpa (the moving of the waist left and right along with the body while doing Cholom), namba (placing the waist in downward position) and tingba (keeping the waist straight) 
- Hands from wrist to five fingers - Based on the flexibility of the hands from wrist to the whole five fingers, two different names are identified, viz. tingba (making the fingers straight) and noppa (making the fingers flexible)

- Arm - The arm carries another importance in getting the correct posture of doing cholom. Two different positions of keeping the arm are witnessed viz. phanba (the arms are kept broad) and shuppa (the arms are kept narrow)

- Elbow - The elbow is always put in the middle position, not too short and not too long to get the right kind of body movement (mayai oiba mawongda thamme)

3) The body below waist (Legs along with buttock) - In this third division of the body parts, five more sub-divisions are done, carrying different roles in doing nata-sankirtana performance.

- Buttock - The position of the buttock needs careful consideration while doing cholom as it will give the correct and rightful way of body posture in performance. So, three different types are identified on how the buttock is placed while doing cholom viz. ning faaba (the buttock is held tight not to move on any side), ning namba (the buttock is kept downward), and ning inthaba (the buttock is moving backward)

- Thigh - Having a firm and muscled- thigh is also essential in doing creative and artistic cholom. Six different names are given based on the placing of the thigh in different body movements viz. namba (the thigh is held tight, which is similar to keeping the waist), thanggatpa (moving one leg upward), hunna thanggatpa (putting one leg upward instantly), thanggatna leiba (circling the body in standing position), namlei (moving the body by keeping the body in low position) and pheimai mannaba (keeping the thigh and the knee in the same level of height)

- Knee - The knee is always put in the front part while doing cholom. Three different types are used on where the knee is used in natasankirtana performance viz. baag leiba (keeping both the knees on the surface and circling the whole body), khuk-u khudak kunba (keeping the knees on the surface and the remaining legs on the back position) and khuk-u naamma taraga ninggongna phamduna leiba (keeping the left knee on the surface, the remaining leg touching the buttock and sitting, and the right leg is held in the sitting position)

- Calf - The calf of the leg is always placed in a broad and elongated manner to obtain an accurate posture for doing body movements (chaona thamba)

- Heel and Toe - While doing different body movements, the heel is placed in the normal balanced position, and the toes are put somewhat higher from the normal area. (khongdonna mathakta haigatla khutningna leitaduna netpa) 


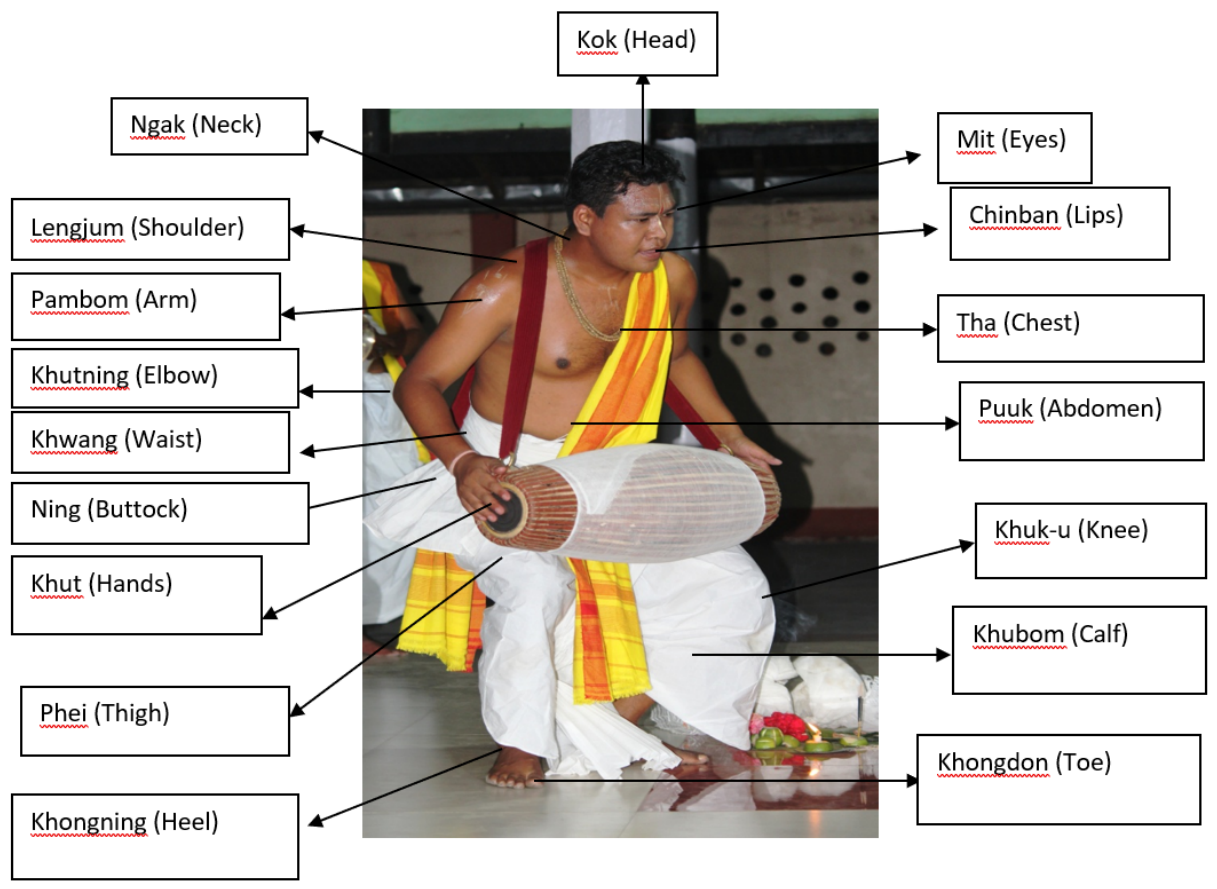

Figure 5 Different parts of the body used in performing Pung Cholom

The learner needs to have some basic foundations on how to play Pung. After having the basics of playing Pung, it is followed by developing different motor skills for doing Pung Cholom. Before learning the Pung Cholom directly, it requires other body-making skills to get the exact body structure, position, and gestures.

1) 5 different types of khurumba (obeisance or bhakti prayer) used in natasankirtana performance and tradition, they are: -

- Panchanga Pranam- obeisance touching five parts of the body to the land. The manner of doing it is in the crawling position.

- Ashthanga Pranam- obeisance touching 8 parts of the body to the land. The whole body is spread on the surface while bowing, but only eight parts touch the ground.

- Dandavad Pranam- prostrate (lying stretched out on the ground with face downward in token of total submission while praying).

- Mannashik Pranam- prayer inside mind, heart, and soul. Obeisance is done in a thinking manner without actual speaking

- Bachanik Pranam- prayer through singing or speaking, salutation to Guru, salutation to the audience

2) 3 different phampham (sitting positions)

- Tarpan phampham (sitting by bending the right knee close to the chest and the left leg kneeling with toes up or down)

- Phampretnanaa phamba (Heel sitting but keeping the toes down)

- Khonggangnanaa phamba (Heel sitting position or kneeling) 
3) 3 different Cholom Phithup (posture and positions of the body)

- Phirep phithup (standing in normal position with toes pointed out)

- Pheithek phithup (sitting in a squatting manner up to the level where the wrist touches the knee)

- Pheithup phithup (sitting in a squatting manner where the elbow of the hand touches the knee)

After developing such skills, the rhythmic movement of legs at the same standing position is carried out. Then, the movement of legs on the right and the left side to and fro in a straight line and semi-circle along with the placement of head, eyes, lips, shoulder, chest, buttock, etc., are developed with the required gestures. In this way, different basic motor skills for doing Pung Cholom are developed. With regular and stiff work practice and experience using these foundational skills, more creative body movements can also create a unique performance.

\section{CONCLUSION}

The findings and analysis, along with the introductory portion of this paper, will clearly and easily indicate how Pung Cholom is done and the motor skills involved in performing it. Different parts of the body are involved in doing Manipuri Pung Cholom. Each part makes up the complete whole-body movements. This performing art form first requires learners to have a clear basic foundation on how to play Pung. After acquiring the basics, different motor skills for learning Pung Cholom are developed. Without such systematic learning of different motor skills, doing creative Pung Cholom and developing into many artistic performances is impossible. So, Pung Cholom is performed with proper coordination of body movements and playing of Pung simultaneously in a rhythmic pattern. The intricate movements of Thang-Ta (Manipuri sword-spear martial art) are incorporated in Pung Cholom performance, making similarities in body gestures and footwork. In its form, position structure of the body, it resembles Mukna (an indigenous Manipuri wrestling sport form). As a result, all the body movements of Pung Cholom are vigorous and energetic, added with bhakti, devotion, grace, poise, acrobatic, and delicacy, which enchants the viewers. This particular study will bring out the different aspects of Manipuri Pung Cholom helping in the learning area of psychomotor skills. It gives global benefits in the sphere of performing arts.

\section{REFRENCES}

Chaobhal, E. (2002). Cholom (1st ed.). Imphal : Laihui Publishers.

Chaobhal, E. (2010). Nata Cholom Wamachang (1st ed.). Imphal : Chaobhal Publishers.

Danisana, R. (2012). Manipuri Dances [A Panorama of Indian Culture] (1st ed.). New Delhi : Rajesh Publications.

Dhaka, L. (2007). Manipuri Nata Sankirtana Eshei Sheirol (1st ed.). Thoubal : Dhaka Publications.

Ibungohal, L., \& Khelchandra, N. (1989). Cheitharol Kumbaba. Imphal : Manipuri Sahitya Parishad.

Kerr, R. (1982). Psychomotor Learning. New York : CBS College Publishing. 
Nilakanta, E. (1982). Aspects of Indian Culture (1st ed.). Imphal : JN Manipur Dance Academy.

Nilakanta, E. (1991). Manipuri Performing Art. In N. Sanajaoba (Ed.), A Vaishnavite Approach : Manipur Past and Present 2, 258. Delhi : Mittal Publication.

Parratt, S. N. (1980). The Religion of Manipur. Calcutta : Firma KLM Private Limited.

Radharani, E. (2012). A Study on Nata Sankirtana of Manipur. Imphal : Department of Dance, Manipur University.

Sharma, A. C. (2002). Manipuri Nata Sankirtana Vichar Anesuba Saruk (1st ed.). Imphal : Chitreswar Sharma Publication.

Sharma, A. C. (2012). A Collection of Nata Sankirtan and Its Related Forms (1st ed.). Imphal : JN Manipur Dance Academy.

Shyamchand, N. (2004). Nata Sankirtana Sheisak Sheihou (1st ed.). Imphal : Shyamchand Publication.

Singh, M. T. (2016). Manipuri Nata Sankirtana As A Mahayajna. Voice of Research, V (3), 12-15.

Thoiba, M. (2014). Facets of Manipuri Culture (1st ed.). Imphal : Yaibiren Communications. https://dx.doi.org/10.29121/shodhkosh.v2.i2.2021.49

Waikhom, R. (2004). A Historical Study of Traditional Manipuri Theatre (From Ancient Times to 1947). Imphal : Manipur University.

Wuest, D. A., \& Bucher, C. A. (2010). Foundations of Physical Education, Exercise Science, and Sport. New Delhi : Tata McGraw Hill Education Private Limited. 